\title{
Phase behavior, interaction and properties of acetic acid lignin-containing polyurethane films coupled with aminopropyltriethoxy silane
}

\author{
H. H. Wang ${ }^{\mathrm{a}, \mathrm{b}^{*}}, J . M o u^{\mathrm{a}}, Y . H . N i^{\mathrm{b}}$, G. Q.Fei ${ }^{\mathrm{a}}$, C. L. Si $i^{\mathrm{c}}, J . Z o u^{\mathrm{a}}$ \\ ${ }^{\text {a}}$ Key laboratory of Auxiliary Chemistry \& Technology for Chemical Industry, Ministry of Education. Shaanxi University \\ of Science \& Technology, 710021, Xi' an Shaanxi, China \\ ${ }^{b}$ Limerick Pulp and Paper Center, University of New Brunswick, E3B 5A3 Fredericton, NB, Canada \\ ${ }^{\mathrm{c}}$ Tianjin Key Laboratory of Pulp and Paper, Tianjin University of Science and Technology, 300457 Tianjin, China
}

Received 4 December 2012; accepted in revised form 2 February 2013

\begin{abstract}
A series of novel acetic acid lignin-containing polyurethane (LPU) films coupled with aminopropyltriethoxy silane (APTS) (LPUSi) or the mixture of APTS and trimethylol propane (TMP) (LPUSiT) were prepared. With 2\% APTS addition, the crosslinking density increased, and the resultant films were endowed with good mechanical properties and water resistance. It was also found that the hydrogen bonding interaction between $-\mathrm{NH}$ and $-\mathrm{C}=\mathrm{O}$ of urethane was destroyed, and new hydrogen bonds between APTS and LPU were formed. However, when APTS content was greater than $4 \%$, significant phase aggregation were detected, resulting in poor mechanical properties and water resistance. In contrast, the crosslinking density, tensile strength and water resistance can be further improved with TMP addition at 2\% APTS. The simultaneous addition of APTS and TMP was beneficial for phase mixing and the formation of uniform network. And the surface morphology of LPUSiT films became smoother and more homogeneous.
\end{abstract}

Keywords: polymer composites, acetic acid lignin, polyurethane, aminopropyltriethoxy silane, crosslinking

\section{Introduction}

The world plastics consumption has consistently grown for decades and was about 268 million tonnes in 2007 [1]. Production of polymers has long relied on fossil resources to provide raw materials. Usage of fossil oil is directly associated with environmental issue. In addition, the ever declining fossil reserves and increasing demand have caused the skyrocketing of the price of petroleum product [2]. Therefore biomass becomes a promising resource that can replace fossil oil for sustainable production of chemicals [3]. Lignin, as one of the most abundant aromatic biopolymers [4-5], constitutes about 15$30 \%$ of the wood and $12-20 \%$ of the annual plants [6]. Due to the renewable and biodegradable nature, wide availability, non-agricultural based economy and reactivity, the utilization of lignin as a source of polymeric materials attracts more and more attention, albeit in different molecular weights and specific structures caused by the chemical processes associated with the production of cellulose pulp for papermaking [7].

Organosolv methods are recognized as viable sulfurfree alternatives to traditional pulping techniques. Oxoacid-based method has been demonstrated to be among the most successful method which allows efficient delignification of both woody [8-9] and non-woody materials [10]. Two oxoacids have achieved particularly good delignification result: formic acid [11-14], and acetic acid [10, 15]. Acetic

\footnotetext{
*Corresponding author, e-mail: wseaflower@126.com

(C) BME-PT
} 
acid acidolysis method is shown to be an efficient method to extract lignin with better yield and much lower content in impurities than for conventional acidolysis [16]. Pulp yields for the acetic acid treatment are also demonstrated to be higher than for formic acid [10]. In addition, conventional hydrolysis modifies the lignin polymer, causing the cleavage of some aryl-ether linkages. While acetic acid method is less damaging [16], the resulting partial acetylation of primary alcoholic groups has to be regarded as a non-negative point when considering further analytical characterization.

The use of lignin fragments as such, or after suitable chemical modifications, as macromonomers has been extensively investigated through the implication of both their phenolic and aliphatic hydroxyl groups to prepare polyurethanes [7]. A wide range of lignin-based polyurethane materials, such as rigid foams [17], hydrogels [18] and elastomers, have been synthesized and the corresponding mechanical and thermal properties have been evaluated. With respect to lignin-derived polyurethane plastics, most researches focused on Alcell lignin [19], kraft lignin [20]. Ciobanu et al. [21] prepared a series of flax soda lignin/polyurethane blends by solvent casting technique from dimethylformamide solutions. Better thermo-mechanical properties were found for the $4.2 \mathrm{wt} \%$ lignin-containing blend. Films containing more than $9.3 \mathrm{wt} \%$ lignin were heterogeneous. Ni et al. [19] synthesized Alcell ligninbased polyurethane with and without a polymerization catalyst. Hatakeyama et al. [22] obtained polyurethane from alcoholysis and kraft lignin-based polycaprolactones. Zhang and Huang [23] found that polyurethane-nitrolignin (NL) film with $2.8 \%$ nitrolignin which was prepared by tetrahydrofuran solution casting was most miscible, and its tensile strength was 2 times higher than that of PU films. A suitable content of NL plays an important role in the promotion of PU network formation, resulting in the enhancement of crosslinking density, whose contribution effectively enhances strength and hardness. Heretofore there are only few reports related to acetic acid lignin-containing polyurethane films, which have potential application in plastics [24-25]. Effects of acetic acid lignin content and annealing on mechanical and thermal properties were simply investigated, it was demonstrated PU containing
$20 \%$ acetic acid lignin possesses better tensile strength. While at higher lignin content, the corresponding PU became hard and brittle.

Preparation of polyurethane films from lignin is not an easy process because of the structure of lignin, which on direct reaction with isocyanate gives brittle polyurethane [26]. In order to improve the lignin content in PU formulation for a product with suitable performance and extensive application, oxypropylation of lignin has been recognized as a promising method [20]. However, the high cost associated to the implementation of such chemical modification processes makes difficult to endow lignin with a high added value, delaying the industrial exploration of this renewable polymer [6]. In addition, linear polyols with high molecular weight are often incorporated into PU backbone to overcome the above shortcomings. For polyol with very high molecular weight, the efficiency decreases again as a result of increasing dilution factor of hydroxyl groups [4, 27]. Under such circumstances, how to make the network formation more efficient and increasing lignin content in PU become critical in increasing the mechanical properties of lignin-containing PU. In our previous studies, a maximum acetic acid lignin (AL) content of $43.3 \%$ can be reached for the continuous polyurethane film formation [28]. The incorporation of trimethylol propane (TMP) and 3aminopropyltriethoxysilane (APTS) is demonstrated to be beneficial to the thermal property of AL-containing polyurethane (LPU) films. Based on the information mentioned above, we used the acetic acid lignin on an 'as received' basis with no pretreatment or modification. The objective was to gain fundamental knowledge of chemistry and physics of the network formation of LPU films, and compare the properties of AL-containing polyurethanes coupled with APTS and TMP of different contents. To our best knowledge, APTS and TMP haven't been simultaneously introduced into LPU system to improve the corresponding properties. In this study, effects of APTS content and TMP on the crosslinking density, morphology, hydrogen bonding, phase behavior, water resistance and mechanical properties of ALcontaining polyurethane films were systematically investigated. These results can provide fundamental information for optimization of acetic acid lignincontaining polyurethane films. 


\section{Experimental section}

\subsection{Materials}

Methylene diphenyl diisocyanate (MDI), polyethylene glycol (PEG, the number average molecular weight was $1000 \mathrm{~g} \mathrm{~mol}^{-1}$ ), 3-aminopropyltriethoxysilane (APTS), trimethylolpropane (TMP) and N, $\mathrm{N}$-dimethylacetamide (DMAc) were purchased from Aldrich Chemicals Co. Inc. (Canada). The abovementioned materials were of analytical grade and were directly used without further purification. Acetic acid, $\mathrm{HCl}$, dioxane and diethyl ether were also purchased from Aldrich Chemicals Co. Inc. (Canada).

\subsection{Preparation and characterization of acetic acid lignin}

Spruce wood chips were submitted to a treatment with $90 \%$ acetic-acid solutions $(500 \mathrm{~mL})$ catalyzed by small amount $(0.6 \%)$ of $\mathrm{HCl}(8.3 \mathrm{~g})$. Experiments were performed at boiling temperature using a liquor/wood ratio equal to $5 \mathrm{~g} / \mathrm{g}$ for $3 \mathrm{~h}$. Subsequently they were cooled to room temperature [28]. The spent liquor obtained by filtration was concentrated through rotary vacuum evaporator at $60^{\circ} \mathrm{C}$, and approximately $100 \mathrm{~mL}$ concentrated sample was obtained, thereafter, $900 \mathrm{~mL}$ deionized water was added to precipitate the dissolved lignin. After $24 \mathrm{~h}$, brown acetic acid lignin (AL) was obtained by filtration.

The lignin samples were acetylated before gel permeation chromatography (PL-GPC 50, England). The average number molecular weight $\left(M_{\mathrm{n}}\right)$ of $\mathrm{AL}$ was $3515 \mathrm{~g} \mathrm{~mol}^{-1}$; the average weight molecular weight was $6215 \mathrm{~g} \mathrm{~mol}^{-1}$ and the polydispersity index (PDI) was 1.768. Carboxylic, phenolic and aliphatic hydroxyl group contents were determined by nonaqueous potentiometric titration and ${ }^{1} \mathrm{H}$ NMR spectrometry (Bruker Advanced $400 \mathrm{MHz}$ spectrometer, Germany) of the acetylated lignin [10]. The content of phenolic and aliphatic hydroxyl group was 4.96 and $4.57 \mathrm{wt} \%$, respectively; and the content of carboxylic group was $5.76 \mathrm{wt} \%$.

\subsection{Preparation of AL-containing polyurethane}

AL, TMP and PEG were dissolved in DMAc. MDI was added dropwise into the system. The mixture was kept stirring in a water bath at $60^{\circ} \mathrm{C}$ for $2 \mathrm{~h}$. Then the temperature was increased to $70^{\circ} \mathrm{C}$. After $1.5 \mathrm{~h}$, different contents of APTS were added and
Table 1. Chemical composition of AL-containing polyurethanes

\begin{tabular}{|l|c|c|c|c|}
\hline \multicolumn{1}{|c|}{ Sample } & $\mathbf{n}(\mathbf{N C O}) / \mathbf{n}(\mathbf{O H})$ & $\begin{array}{c}\text { Lignin } \\
{\left[\mathbf{\%}^{\mathbf{a}}\right.}\end{array}$ & $\begin{array}{c}\text { APTS } \\
{\left[\mathbf{\%}^{\mathbf{b}}\right.}\end{array}$ & $\begin{array}{c}\text { TMP } \\
{\left[\mathbf{\%}^{\mathbf{b}}\right.}\end{array}$ \\
\hline LPU & $1.7: 1$ & 43.3 & 0 & 0 \\
\hline LPUSi1 & $1.7: 1$ & 43.3 & 1 & 0 \\
\hline LPUSi2 & $1.7: 1$ & 43.3 & 2 & 0 \\
\hline LPUSi3 & $1.7: 1$ & 43.3 & 4 & 0 \\
\hline LPUSi4 & $1.7: 1$ & 43.3 & 5 & 0 \\
\hline LPUSiT & $1.7: 1$ & 43.3 & 2 & 1 \\
\hline
\end{tabular}

${ }^{\mathrm{a}}$ with respect to $\mathrm{PEG}$.

${ }^{b}$ with respect to total monomer mass.

the reaction was continued for another $0.5 \mathrm{~h}$. The experimental conditions for preparing AL-containing polyurethane are given in Table 1 . The experiment schemes and model of AL-containing polyurethane were illustrated in Figure 1 and 2, respectively.

\subsection{Preparation of AL-containing polyurethane films}

After the polymerization, the solution was immediately transferred to a polytetrafluoroethylene (PTFE) plate, which was allowed to dry at room temperature for 2 days and then at $100^{\circ} \mathrm{C}$ for $6 \mathrm{~h}$. After demolding, the film was submitted to vacuum drying over phosphorous pentoxide for 5 days.

\subsection{Swelling test}

Samples of approximately $3 \mathrm{~mm} \times 3 \mathrm{~mm}$ were immersed in glass flasks containing dimethyl formamide (DMF) and allowed them to stand at ambient temperature. After 5 days equilibrium, samples were removed from DMF and patted with lint-free tissue paper to remove excess solvent, and the dimensions were measured again. The crosslink density $\left[\mathrm{mol} / \mathrm{cm}^{3}\right]$ of the $\mathrm{NCO}-\mathrm{OH}$ bonds for each specimen was estimated using Equation (1) which was proposed by Flory and Rehner [19, 29]:

$$
\frac{\nu_{\mathrm{c}}}{V_{0}}\left[\frac{\mathrm{mol}}{\mathrm{cm}^{3}}\right]=\frac{-2\left[\nu+\chi \nu^{2}+\ln (1-\nu)\right]}{V_{1}\left(2 \nu^{1 / 3}-\nu\right)}
$$

where $v_{\mathfrak{c}}$ is the effective number of moles of crosslinked chains, $V_{1}$ is molar volume of solvent, $\chi$ is the polymer-solvent interaction parameter, $v$ is the volume fraction of polymer in swollen gel $(v=$ $\left.V_{0} / V\right), V_{0}$ is volume of dry polymer, and $V$ is volume of swollen gel at equilibrium.

In order to determine $\chi$ for our polyurethane-DMF system, swelling tests were carried out at 25,30 and 


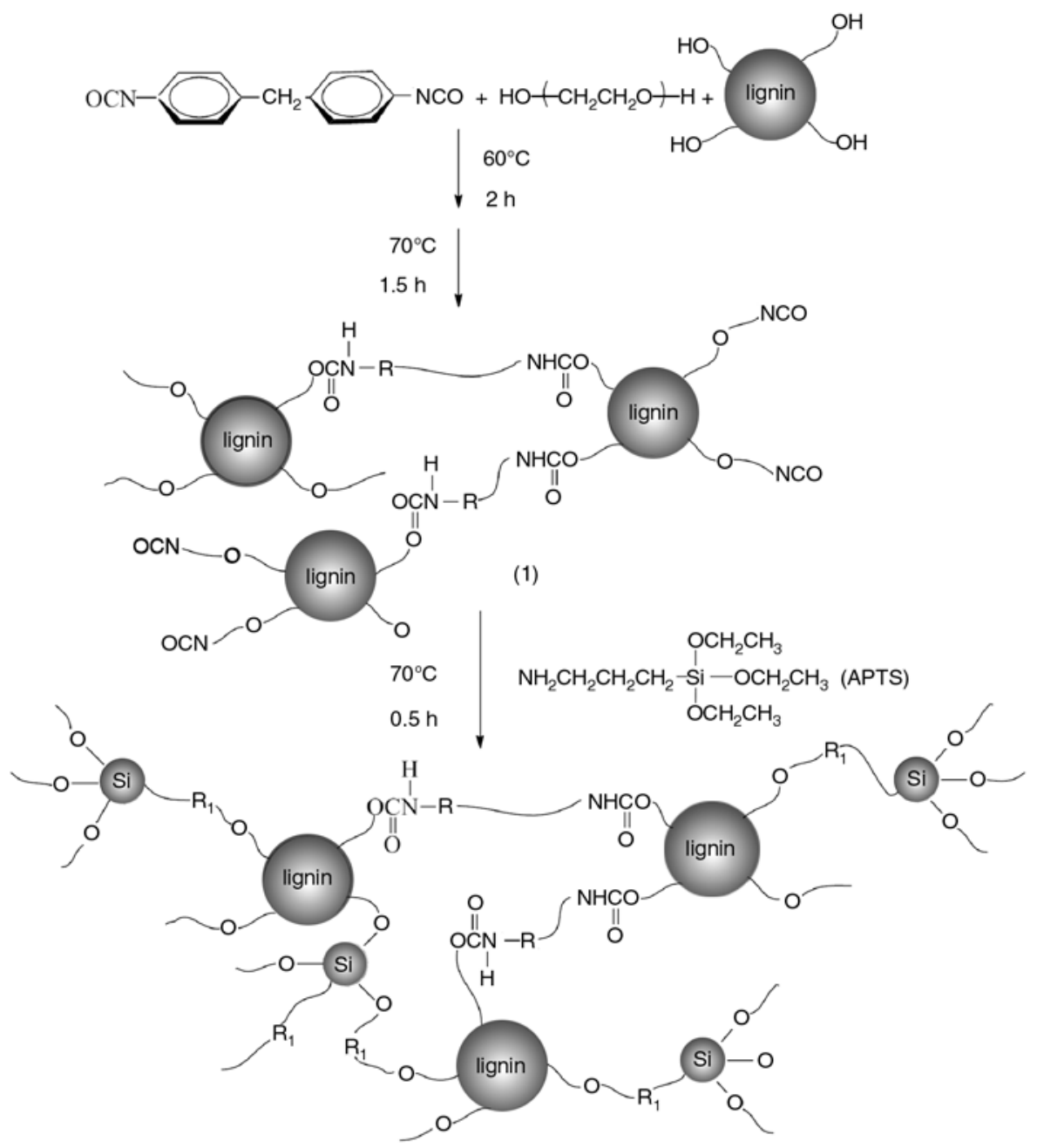

(2)

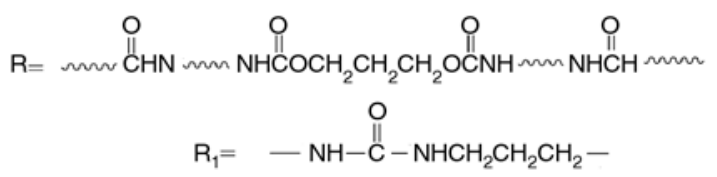

Figure 1. Experimental scheme and model for AL-containing polyurethane modified with APTS

$35^{\circ} \mathrm{C}$. From the temperature dependency of the swelling volume, $\chi$ value was obtained according to Equation (2). In the present study, the polymer-solvent interaction parameter $(\chi)$ was determined to be 0.49:

$\frac{\delta \ln \nu}{\delta \ln T}=\frac{-3 \chi(1-\nu)}{5(1-\chi)}$

\subsection{Characterization}

Fourier transform infrared (FT-IR) spectra of all samples were recorded on an American Perkin-Elmer spectrum 100 FT-IR spectrometer in the range of $4000-500 \mathrm{~cm}^{-1}$.

Dynamic mechanical analysis (DMA) was performed on an American TA DMA Q800 dynamic mechanical analyzer with a clamp type of tension film. The heating rate was maintained at $3^{\circ} \mathrm{C} / \mathrm{min}$ from -110 to $200^{\circ} \mathrm{C}$. The strain and frequency were $0.04 \%$ and $1 \mathrm{~Hz}$ respectively.

The tensile strength $(\sigma)$ was measured on a CMT6503 universal testing machine (Shenzhen SANS Test Machine Co. Ltd., Shenzhen, P.R. China) with a crosshead rate of $200 \mathrm{~mm} / \mathrm{min}$ according to GB13022-91. An average of five replicates of each sample was taken.

Environmental scanning electron microscope (ESEM), coupled with an EDAX energy dispersive X-ray (EDX) system, was carried out on a Hitachi SU-70 SEM (Japan). The surface of polyurethane films was coated by carbon to remove the side effect of charge. 


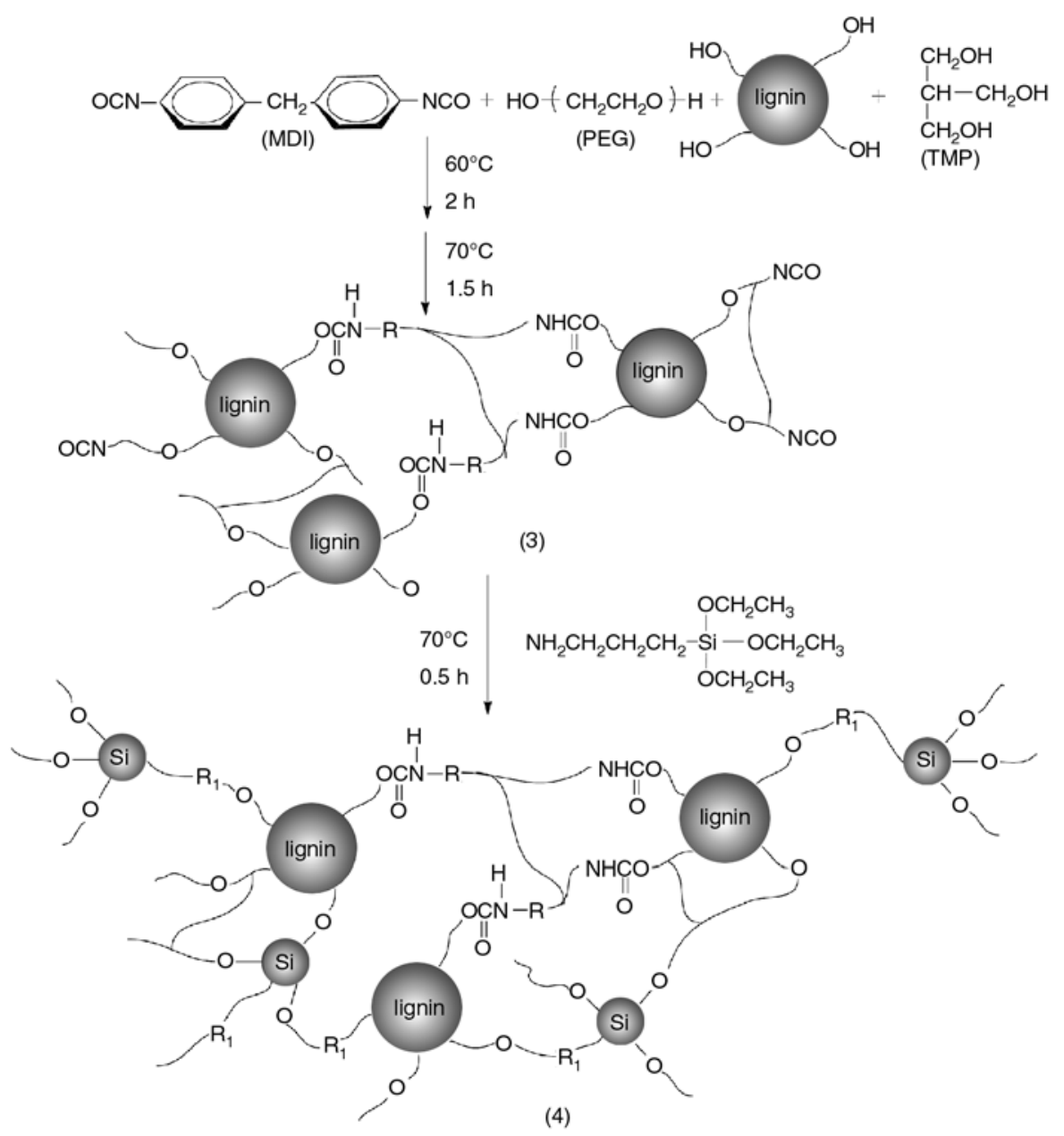

Figure 2. Experimental scheme and model for AL-containing polyurethane modified with APTS and TMP

Angular dependent X-ray photoelectron spectroscopy (XPS) was performed on a Perkin-Elmer physical Electronic Model 5400 (America) with a hemisphere analyzer and a position sensitive detector. The spectrometer was equipped with an $\mathrm{Mg} / \mathrm{Ka}$ $(1253.6 \mathrm{eV})$ achromatic X-ray source operated at a power of $400 \mathrm{~W}$ and angles $45^{\circ}$ were used with the $\mathrm{X}$-ray source. Pass energy of $89.45 \mathrm{eV}$ was chosen for all angle-dependent acquisitions. The spectrometer was typically run at the $6.7 \cdot 10^{-7}$ Torr vacuum range. A wide scan $(0-1000 \mathrm{eV})$ was recorded for each sample.

Contact angles were measured with a JJC-I contact angle goniometer (Chengde Tester factory, P.R. China) at $25^{\circ} \mathrm{C}$ with water as medium.

The AL-containing polyurethane films were cut into circular disks by using a sharp-edged stainless steel die with inner diameter of $20 \mathrm{~mm}$. The samples were dried in vacuum oven for $24 \mathrm{~h}$ to determine their dry weight $(W)$. Absorption of films was determined by immersing the films in a beaker of water for $24 \mathrm{~h}$. After wiping off the surface water with a piece of filter paper, its weight $\left(W_{1}\right)$ was determined. The water absorption (WS) of the films was calculated by Equation (3):

$$
\mathrm{WS}=\frac{W_{1}-W}{W} \cdot 100 \%
$$

\section{Results and discussion \\ 3.1. Crosslinking density and mechanical properties}

The crosslinking density and tensile strength of LPU films modified with different APTS and TMP contents are shown in Table 2. It is reported that crosslinking density has important effects on mechanical property, thermal behavior and water resistance of lignin-containing polyurethane films $[19,23]$, all of which are important characteristic parameters for polymeric materials. The crosslinking density is determined from swelling tests in DMF as described previously. Since DMF is a very strong solvent for lignin, lignin that is not incorporated into the polymer network will be dissolved to 
produce a dark colored solution [19]. In this study, the absence of a colored solution suggests that acetic acid lignin is an active ingredient in the polyurethane system. At a given lignin content, the crosslinking density increases from $3.10 \cdot 10^{-4}$ to $3.88 \cdot 10^{-3} \mathrm{~mol} \mathrm{~cm}^{-3}$ when APTS content increases from 0 to $2 \%$. As the APTS content increases, more reactive groups $(-\mathrm{SiOH})$ are generated by the hydrolysis of trialkoxy groups in APTS, which are available to crosslink with isocyanate groups and hydroxyl groups, resulting in dramatic increase in the crosslinking density (as shown in Figure 1). The increased crosslinking density is generally responsible for increasing strength, therefore the tensile strength of corresponding films increases from 16.2 to $22.9 \mathrm{MPa}$.

Further increase in the APTS content from 2 to $5 \%$ does not strengthen, but even lead to inferior tensile strength. It is also found that the crosslinking density decreases from $3.88 \cdot 10^{-3}$ to $1.64 \cdot 10^{-3} \mathrm{~mol} \mathrm{~cm}^{-3}$. This is probably due to over-crosslinking of LPU network and the lack of uniformity distribution of APTS in AL-containing polyurethane. APTS is likely to self-aggregate instead interact with ALcontaining polyurethane chains at higher APTS content. This behavior is also confirmed by FT-IR and ESEM studies (as shown in Figure 3 and 4), and suggests a phase-separated morphology for LPUSi when the APTS content is greater than 4\%. At given APTS content, the crosslinking density of LPUSiT increases from $3.88 \cdot 10^{-3}$ to $5.01 \cdot 10^{-3} \mathrm{~mol} \mathrm{~cm}^{-3}$ with TMP addition, resulting in highest tensile strength of $25.6 \mathrm{MPa}$. This might be explained by the fact that the number of available sites for crosslinking in AL-containing polyurethane is insufficient when APTS content is $2 \%$, only a partial network is established. The addition of TMP at the first step is beneficial for the formation of more uniform network, and more reactive groups are thereby participated in the crosslinking to make the network well formed, as shown in Figure 2. The attempt to increase the crosslinking density and tensile strength merely through increasing APTS content is infeasible, which might be attributed to selfaggregative characteristic of APTS. The abovementioned information indicates that there is good synergistic effect between APTS and TMP.

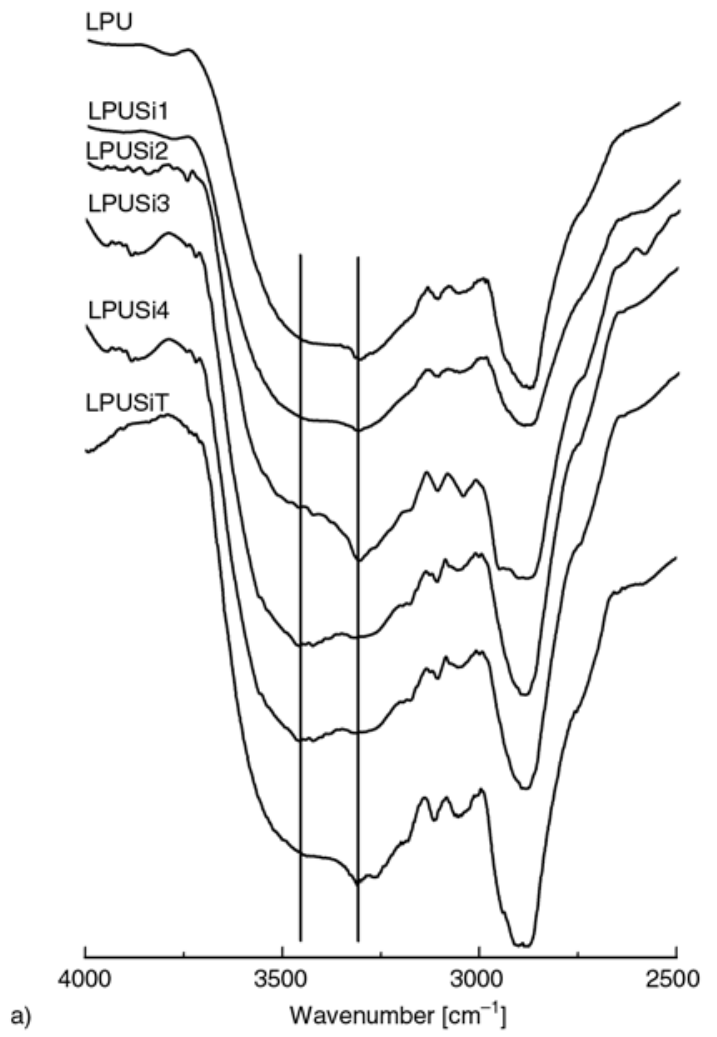

a)

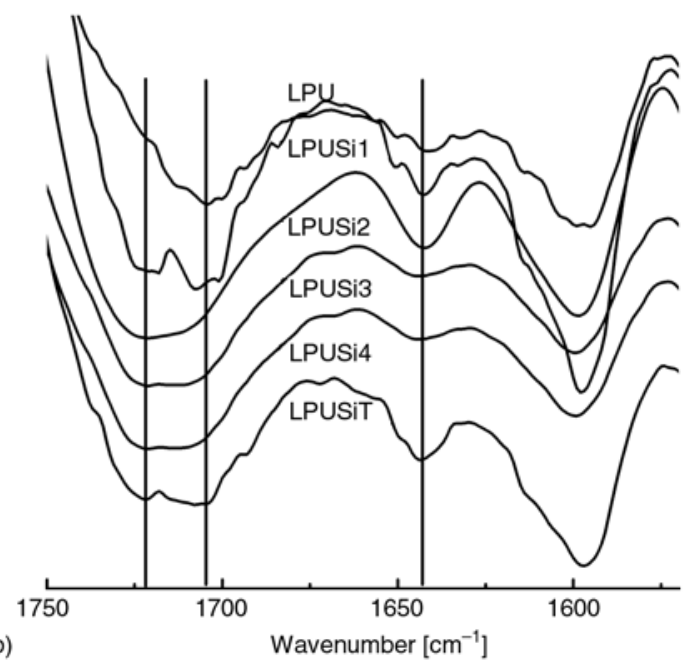

Figure 3. FT-IR spectra of LPU, LPUSi1, LPUSi2, LPUSi3, LPUSi4 and LPUSiT

\subsection{Hydrogen-bonding interactions in LPU, LPUSi and LPUSiT films}

The hydrogen bonding interactions in AL-containing polyurethane were investigated based on the FT-IR technique. It has been extensively reported by many researchers that FT-IR technique is an effective method to characterize the hydrogen bonding in polyurethane [30-31]. The FT-IR spectra of LPU, 

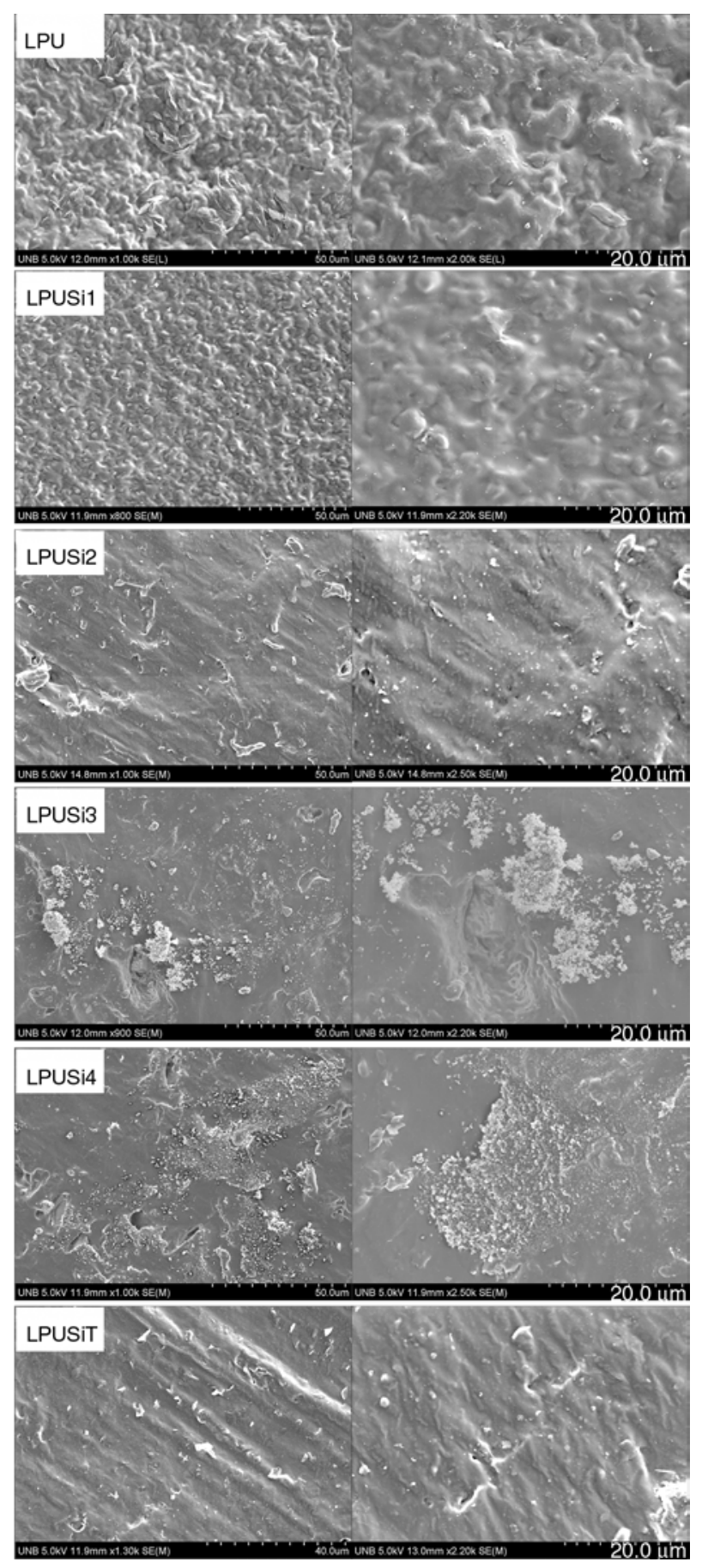

Figure 4. ESEM morphology of LPU, LPUSi and LPUSiT films at different magnification

LPUSi and LPUSiT are shown in Figure 3. The band at about $\sim 3310 \mathrm{~cm}^{-1}$ corresponds to stretching vibration of hydrogen-bonded - NH [32]. The band around $~ 3446 \mathrm{~cm}^{-1}$ is assigned to free $-\mathrm{NH}$ [33-34]. The intensity of hydrogen-bonded $-\mathrm{NH}$ increases with increasing APTS addition from 0 to $2 \%$. Intensity decay in free $\mathrm{N}-\mathrm{H}$ band is apparent for LPUSi2, indicating that most of $-\mathrm{NH}$ groups are involved in the hydrogen bonding. As the APTS content is greater than $4 \%$, the intensity of hydrogen-bonded
$-\mathrm{NH}$ decreases, while the intensity of free $-\mathrm{NH}$ increases.

The stretching bands at $\sim 1721, \sim 1709$ and $\sim 1642 \mathrm{~cm}^{-1}$ are attributed to the absorption of free $-\mathrm{C}=\mathrm{O}$ in urethane, hydrogen-bonded $-\mathrm{C}=\mathrm{O}$ in urethane and hydrogen- bonded $-\mathrm{C}=\mathrm{O}$ in urea, respectively [35-36]. The characteristic absorption of $-\mathrm{C}=\mathrm{O}$ in urea at $1642 \mathrm{~cm}^{-1}$ becomes more pronounced with APTS addition, confirming the reactions between -NCO and APTS [36]. It can be also observed that the intensity increases with increasing APTS content from 1 to $2 \%$, but decreases when APTS content is greater than $4 \%$.

In contrast to hydrogen-bonded $-\mathrm{C}=\mathrm{O}$, the intensity of free $-\mathrm{C}=\mathrm{O}$ is enhanced as to LPUSil and LPUSi2, whereas the intensity of hydrogen-bonded $-\mathrm{NH}$ increases. It indicates that APTS addition results in the damage of hydrogen bonds between $-\mathrm{NH}$ and $-\mathrm{C}=\mathrm{O}$ that are existed in LPU, and new hydrogen bonds between APTS and LPU are formed. The increased intensity of hydrogen-bonded $-\mathrm{NH}$ might result from the hydrogen bonding between $-\mathrm{NH}$ and $-\mathrm{Si}-\mathrm{O}-\mathrm{Si}-($ and/or $-\mathrm{C}=\mathrm{O}$ in urea). For the LPUSi3 and LPUSi4 samples, the intensity of hydrogen-bonded $-\mathrm{NH}$ decreases, as well as the intensity of $-\mathrm{C}=\mathrm{O}$ in urea. It suggests that the hydrogen bonds between APTS and LPU are damaged, due to the phase aggregation between LPU and APTS.

Furthermore, with simultaneous addition of APTS and TMP, the intensity of hydrogen-bonded $-\mathrm{C}=\mathrm{O}$ and hydrogen-bonded $-\mathrm{NH}$ is further enhanced, so is the $-\mathrm{C}=\mathrm{O}$ in urea. This indicates a more uniform network is formed. The results are in good agreement with those of strength and crosslinking density.

\subsection{Morphology analysis}

The morphology of polyurethane (PU) depends on the state of the compatibility and phase behavior between hard and soft segments [37]. The ESEM morphology of LPU, LPUSi and LPUSiT films is shown in Figure 4. As the APTS content increases from 0 to $2 \%$, a transition is evident from rough surface of granular shape to a smooth and more homogeneous surface. It can be attributed to the increased crosslinking density (Table 2), and the more uniform network [38]. As the APTS content increases further to $5 \%$ (LPUSi3 and LPUSi4), the phase aggregation becomes more apparent, resulting in 
Table 2. Effects of APTS and TMP content on crosslinking density and tensile strength

\begin{tabular}{|c|c|c|c|c|c|c|c|}
\hline Sample & $\mathbf{V}_{0}$ & V & $v=\mathbf{V}_{0} / \mathbf{V}$ & $v_{2}$ & $v^{1 / 3}$ & $\begin{array}{c}\text { Crosslinking density } \\
{\left[\cdot 10^{-3} \mathrm{~mol} \mathrm{~cm}^{-3]}\right.}\end{array}$ & $\begin{array}{c}\text { Tensile strength } \\
\text { [MPa] }\end{array}$ \\
\hline LPU & 21.949 & 73.359 & 0.29920 & 0.08952 & 0.66884 & 0.3102 & 16.2 \\
\hline LPUSi1 & 15.122 & 28.889 & 0.52346 & 0.27401 & 0.80593 & 1.9819 & 18.9 \\
\hline LPUSi2 & 24.179 & 38.770 & 0.62365 & 0.38894 & 0.85437 & 3.8818 & 22.9 \\
\hline LPUSi3 & 11.966 & 21.694 & 0.55159 & 0.30425 & 0.82011 & 2.4349 & 12.3 \\
\hline LPUSi4 & 23.194 & 46.671 & 0.49696 & 0.24697 & 0.79209 & 1.6426 & - \\
\hline LPUSiT & 32.740 & 49.357 & 0.66333 & 0.44000 & 0.87212 & 5.0133 & 25.6 \\
\hline
\end{tabular}
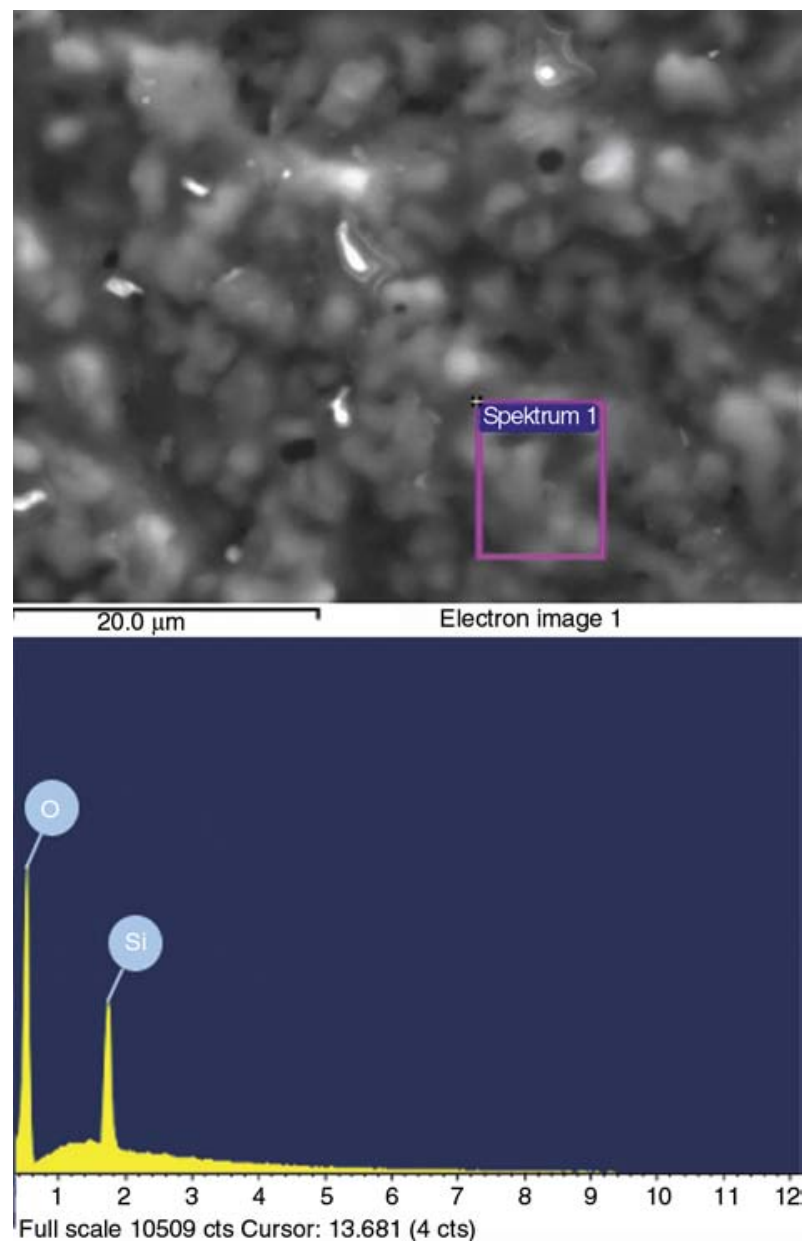

Figure 5. The energy-dispersive spectrum of LPUSi4

inhomogenous surface, as shown in Figure 4. It is found that more precipitated particles are generated on the surface of LPUSi3 and LPUSi4 films. In order to identify the components of the precipitated particles at the higher APTS addition, the EDX spectroscopy is conducted to observe the elemental composition of the precipitated particles, as shown in Figure 5. In addition, the chemical model for LPUSi3 and LPUSi4 are illustrated in Figure 6, respectively. As shown in Figure 5, the main components of the precipitated particles on the surface of LPUSi4 are Si and O elements. It has also been reported by Xia et al. that silica nanoparticles were formed by hydrolysis of the silicon ethoxy groups in water and silanol polycondensation [39]. Therefore, it can be concluded that the precipitated particles on the surface of LPUSi4 are $\mathrm{SiO}_{2}$ particles, which are generated by the hydrolysis of APTS. It also suggests the phase aggregation of excessive APTS on the surface of LPUSi3 and LPUSi4, which may be responsible for the decreased strength and water resistance.

With the addition of both APTS and TMP, the LPUSiT film again shows a smooth and homogenous surface, which is again attributed to the increased crosslinking density and the formation of more uniform network. Increased crosslinking density indicates more hard domains with smaller interdomain spacing, which tends to strengthen the elasticity of network and therefore results in enhancement in mechanical properties. On the other hand, the interaction between domains gets enhanced and phase separation behavior is weakened, therefore more homogeneous films can be obtained [36].

\subsection{Dynamic mechanical analysis}

The temperature dependence of storage modulus $\left(G^{\prime}\right)$ and loss factor $(\tan \delta)$ for LPU, LPUSi and LPUSiT films is shown in Figure 7. The storage moduli of the glassy state for LPU, LPUSi and LPUSiT films are in the order of $10^{3.5} \mathrm{MPa}$, typical for polymer glasses [40]. Highest storage modulus is detected for LPUSiT, since the increased crosslinking density is simultaneously responsible for the increase of rubbery modulus [41].

DMA is also a powerful technique to study initial motion of frozen polymer segments through $\alpha$ relaxation at molecular-level. It is found that $T_{\alpha}$, max increases with the increase of APTS content from 0 to $2 \%$. It suggests that the motion freedom of some chain segments is weakened. The addition of APTS restricts the motion of AL-containing polyurethane chains by virtue of entanglement and newly formed hydrogen bonds between APTS and urethane $-\mathrm{NH}$, 


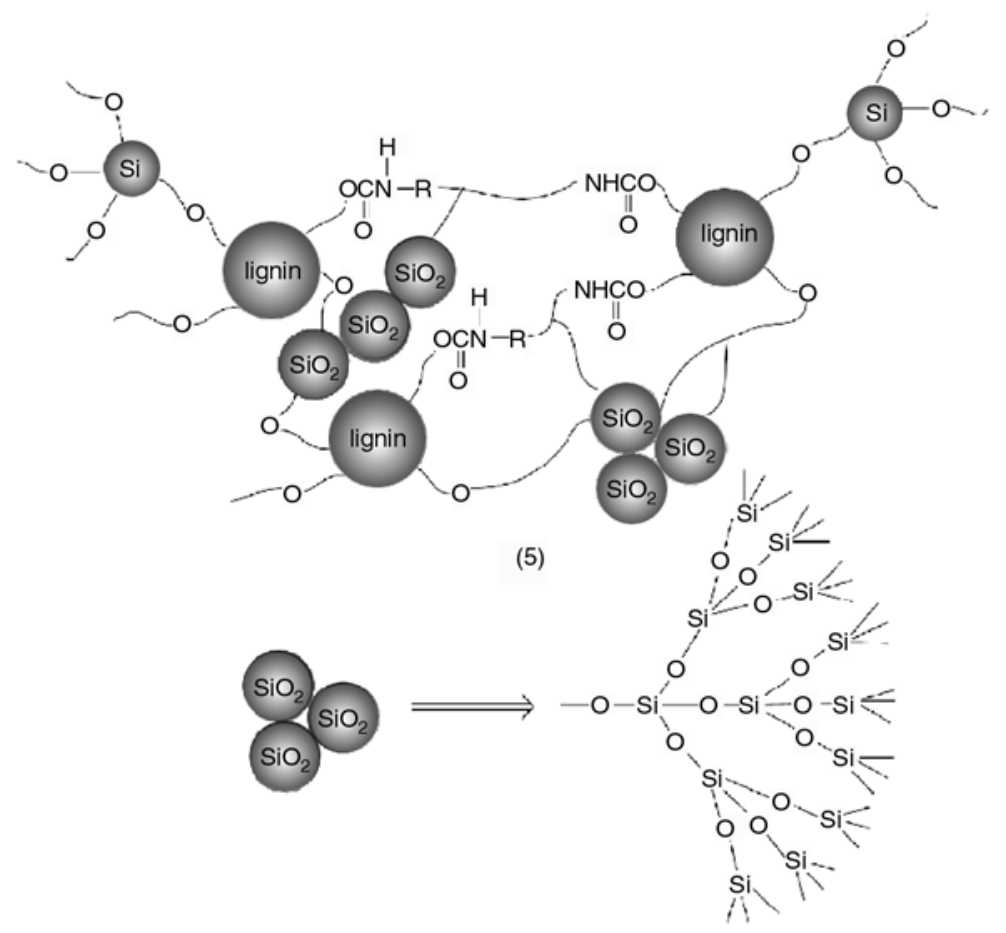

Figure 6. The chemical model for LPUSi3 and LPUSi4
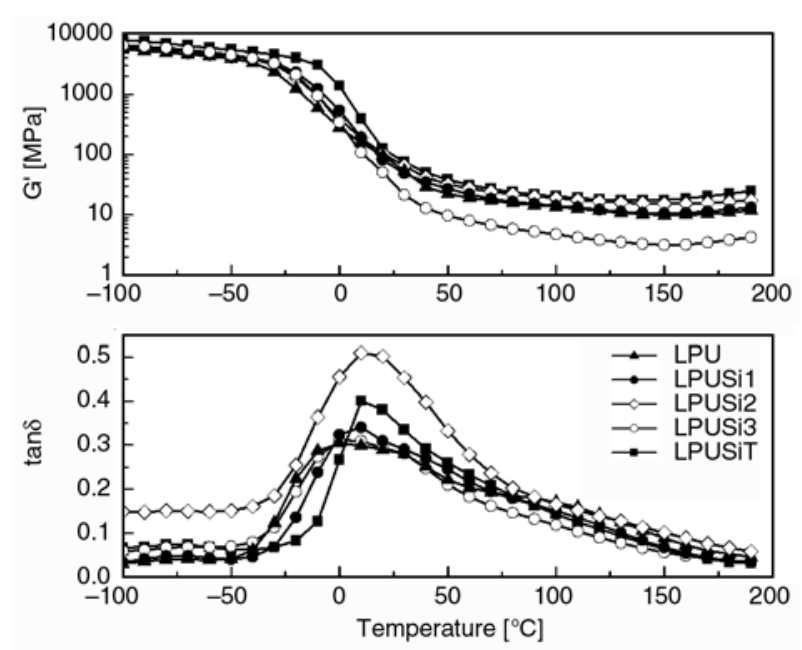

Figure 7. Temperature dependence of storage modulus and $\tan \delta$ for LPU, LPUSi and LPUSiT

also supported by the FT-IR results. The above tendency can also be explained by the increased crosslinking density. The higher the crosslinking density, the more restricted is the main chain motion and thus the higher is $T_{\alpha, \max }$ [41].

However, $T_{\alpha, \text { max }}$ decreases with further increase in APTS content, suggesting that the mobility of soft segment is enhanced. Combined with the increased intensity of free $-\mathrm{NH}$ and free $-\mathrm{C}=\mathrm{O}$ in FT-IR spectra, it can be concluded that hydrogen bonds between $-\mathrm{NH}$ in hard segment and ether oxygen in soft segment are depressed.
It is also found that the height of loss peak increases when APTS content increases from 0 to $2 \%$, showing a tendency of changes similar to $T_{\alpha, \max }$. The losspeak height represents the loss energy required by the motion of frozen segments [31]. It is consistent with the enhanced elongation and decreased Young's modulus, that is, higher toughness [42]. As a result, LPUSi2 and LPUSiT films are endowed with better toughness. However, the phase aggregation of APTS on the surface of films provided the higher motion freedom for soft segments in LPUSi3 and LPUSi4, resulting in lower $T_{\alpha, \max }$ and loss-peak height.

\subsection{XPS analysis}

XPS has been extensively utilized to study the surface functionalization and phase mixing for polyurethane materials [43-44]. The elemental compositions from the XPS survey spectra (Figure 8) and the peak area ratio from the de-convoluted spectra are presented in Table 3 . The high resolution $\mathrm{C} 1 \mathrm{~s}$ XPS spectra of LPU, LPUSi and LPUSiT films are shown in Figure 9. The peaks at binding energies of 96-116, 280-305, 396-416, and 528-548 eV are ascribed to Si2p, C1s, N1s and O1s, respectively [45]. As the APTS content increases, the $\mathrm{C}-\mathrm{O} /$ $(\mathrm{C}-\mathrm{C} / \mathrm{C}-\mathrm{H})$ ratio decreases from 0.919 to 0.510 . It is reported that low surface energy soft segment resides towards the top surface and high surface 
Table 3. Qualitative and quantitative XPS analysis for the surface of LPU, LPUSi and LPUSiT films

\begin{tabular}{|l|c|c|c|c|}
\hline Sample & $\begin{array}{c}\mathbf{C}-\mathbf{O} /(\mathbf{C}-\mathbf{C} / \mathbf{C}-\mathbf{H}) \\
\text { (area ratio) }\end{array}$ & $\begin{array}{c}\mathbf{C}=\mathbf{O} /(\mathbf{C}-\mathbf{C} / \mathbf{C}-\mathbf{H}) \\
\text { (area ratio) }\end{array}$ & Si/C & N/C \\
\hline LPU & 0.919 & 0.0442 & - & 0.0179 \\
\hline LPUSi1 & 0.865 & 0.0585 & 0.0137 & 0.0293 \\
\hline LPUSi2 & 0.776 & 0.0760 & 0.0292 & 0.0339 \\
\hline LPUSi3 & 0.531 & 0.0404 & 0.0327 & 0.0179 \\
\hline LPUSi4 & 0.510 & 0.0343 & 0.0560 & 0.0148 \\
\hline LPUSiT & 0.621 & 0.0292 & 0.0251 & 0.0156 \\
\hline
\end{tabular}

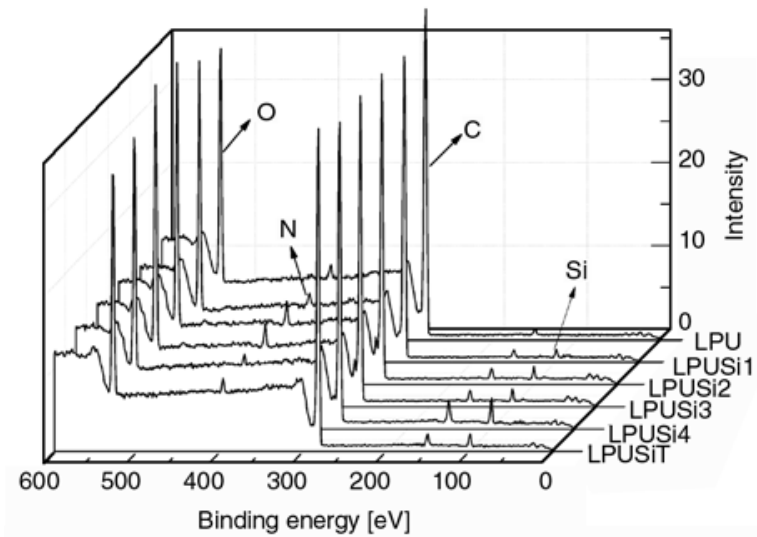

Figure 8. XPS survey spectra of LPU, LPUSi and LPUSiT films

energy urethane/urea component resides inside the bulk of the polymer [44-45]. Therefore, it can be concluded that the addition of APTS promotes the phase mixing of polyurethane.

It can be also observed that the $\mathrm{Si} / \mathrm{C}$ ratio increases with the increase of APTS content. At the same time, the highest $\mathrm{C}=\mathrm{O} /(\mathrm{C}-\mathrm{C} / \mathrm{C}-\mathrm{H})$ and $\mathrm{N} / \mathrm{C}$ ratios are found for LPUSi2 sample. These results suggest the increased interactions between APTS and urethane on the surface of LPUSi2. However, the $\mathrm{C}=\mathrm{O} /(\mathrm{C}-\mathrm{C} / \mathrm{C}-\mathrm{H})$ and $\mathrm{N} / \mathrm{C}$ ratios decrease with further increase in APTS content (LPUSi3 and LPUSi4). Increased $\mathrm{Si} / \mathrm{C}$ ratio, together with lower $\mathrm{C}=\mathrm{O} /$ $(\mathrm{C}-\mathrm{C} / \mathrm{C}-\mathrm{H})$ and $\mathrm{N} / \mathrm{C}$ ratios, indicates weaker interactions between APTS and urethane and thus, enhanced phase aggregation.

Upon the addition of TMP at 2\% APTS (LPUSi2 versus LPUSiT), it is worth noting that the $\mathrm{C}-\mathrm{O} /$ $(\mathrm{C}-\mathrm{C} / \mathrm{C}-\mathrm{H}), \quad \mathrm{C}=\mathrm{O} /(\mathrm{C}-\mathrm{C} / \mathrm{C}-\mathrm{H})$ and $\mathrm{N} / \mathrm{C}$ ratios decrease, accompanied with the decrease in $\mathrm{Si} / \mathrm{C}$, all of which support the enhanced phase mixing with the simultaneous addition of APTS and TMP. It may be also postulated that the APTS surface aggregation may be decreased with TMP addition, as supported by the ESEM and FT-IR results.
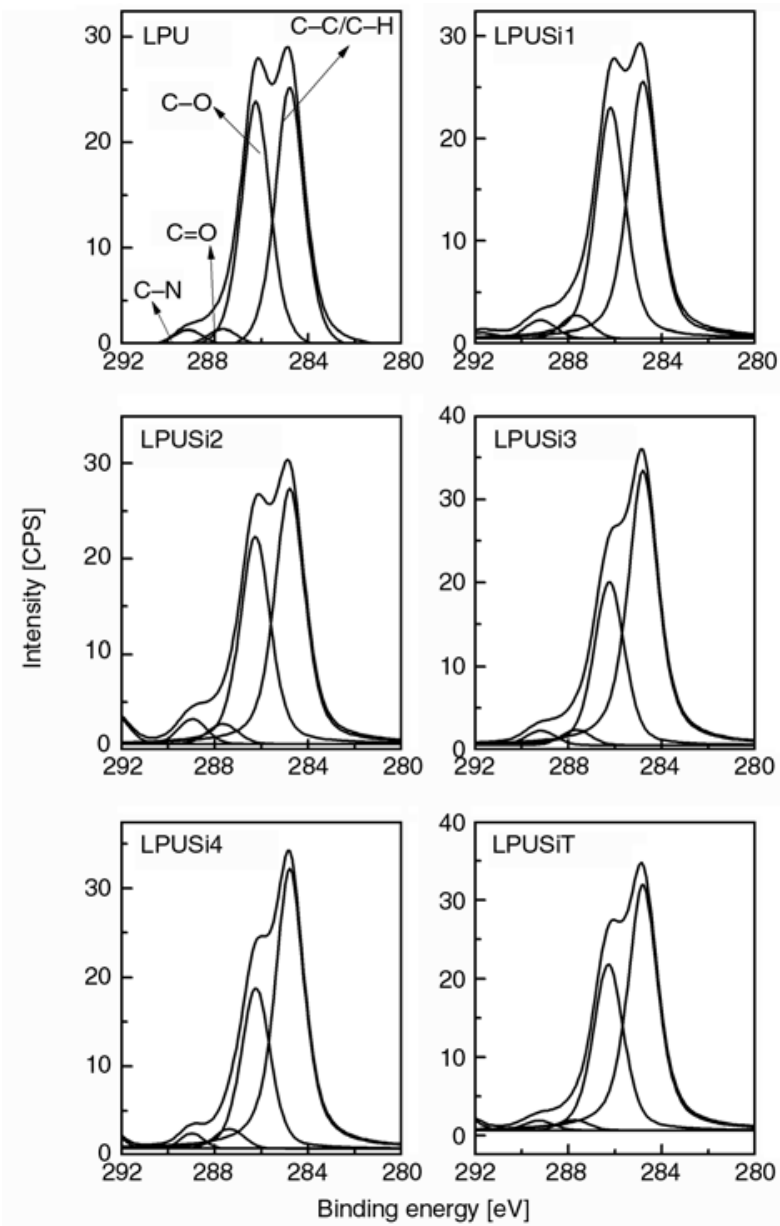

Figure 9. High resolution C1s XPS spectra of LPU, LPUSi and LPUSiT films

\subsection{Water resistance analysis}

As shown in Figure 10, the water absorption decreases from 35.1 to $9.03 \%$ and contact angle increases from 38.1 to $69.7^{\circ}$ when APTS content increases from 0 to $2 \%$, and LPUSi2 with higher crosslinking density is endowed with lower water

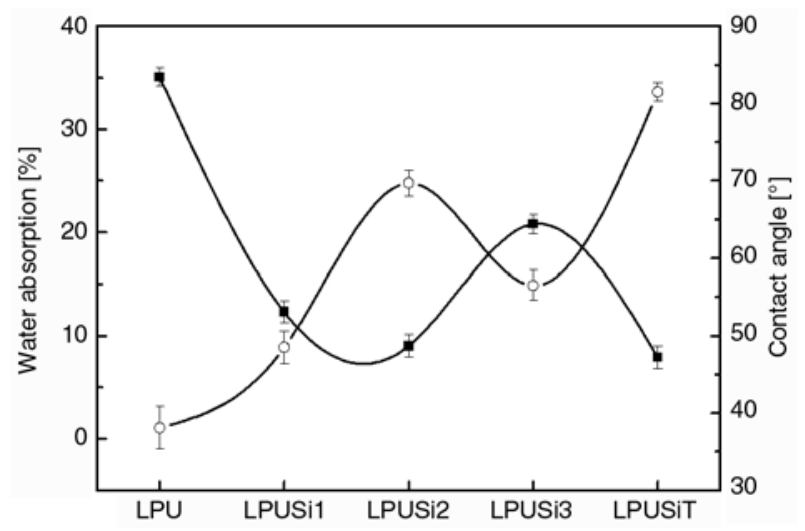

Figure 10. Water absorption and contact angles for LPU, LPUSi and LPUSiT films 
absorption and higher contact angle. It suggests that the increase in the crosslinking density is beneficial for the improvement of water resistance. However, the water absorption increases to $20.8 \%$ and the contact angle decreases to $56.5^{\circ}$ as the APTS content increases to $5 \%$, which can be due to the phase aggregation and decrease in crosslinking density.

The addition of TMP (LPUSiT versus LPUSi2 samples) leads to the decrease of water absorption to $7.92 \%$ and increase of contact angle to $81.5^{\circ}$, which are explained by the increased crosslinking density and more homogeneous surface morphology together with enhanced phase mixing, as discussed in the previous sections.

\section{Conclusions}

Novel acetic acid lignin-containing polyurethane (LPU) films have been synthesized by a simple method without oxyalkylation of lignin. APTS and TMP were utilized instead to form three-dimensional bridge between MDI, PEG and acetic acid lignin. With $2 \%$ APTS addition, the crosslinking density increased from $3.10 \cdot 10^{-4}$ to $3.88 \cdot 10^{-3} \mathrm{~mol} \mathrm{~cm}^{-3}$. The hydrogen bonds that were existed in LPU were damaged, and new hydrogen bonds between APTS and LPU were formed. In addition, smooth and homogenous surface morphology were obtained, which can be attributed to higher crosslinking density and phase mixing degree, the resultant films were endowed with good mechanical property and water resistance. However, further increase in APTS content was not effective to improve the film performance, and decreases in crosslinking density and phase aggregation were detected when APTS content were higher than $4 \%$, resulting in performance attenuation. It was also worth to mention that the crosslinking density of LPUSiT increased from $3.88 \cdot 10^{-3}$ to $5.01 \cdot 10^{-3} \mathrm{~mol} \mathrm{~cm}^{-3}$ with TMP addition at $2 \%$ APTS, resulting in enhanced tensile strength and water resistance. Further systematic study will be made on the synergistic effect of APTS and TMP on the properties of acetic acid-containing polyurethanes.

\section{Acknowledgements}

Funding for this project are from National Natural Science Foundation of China (21204046), NSERC CRD grant (CRDPJ 363811-07), the Canada Research Chairs program, the project sponsored by the Scientific Research Foundation for the Returned Overseas Chinese Scholars, State Education Ministry, Research Foundation of Education Bureau of Shaanxi Province (2010JK440, 2010JK433) and Academic Leaders Cultivation Program of Shaanxi University of Science \& Technology (XSG2010014).

\section{References}

[1] Shen L., Worrell E., Patel M.: Present and future development in plastics from biomass. Biofuel, Bioproducts and Biorefining, 4, 25-40 (2010).

DOI: $10.1002 /$ bbb.189

[2] Naik S. N., Goud V. V., Rout P. K., Dalai A. K.: Production of first and second generation biofuels: A comprehensive review. Renewable and Sustainable Energy Reviews, 14, 578-597 (2010).

DOI: $10.1016 /$ j.rser.2009.10.003

[3] Pan H.: Synthesis of polymers from organic solvent liquefied biomass: A review. Renewable and Sustainable Energy Reviews, 15, 3454-3463 (2011). DOI: $10.1016 /$ j.rser.2011.05.002

[4] Borges da Silva E. A., Zabkova M., Araújo J. D., Cateto C. A., Barreiro M. F., Belgacem M. N., Rodrigues A. E.: An integrated process to produce vanillin and ligninbased polyurethanes from Kraft lignin. Chemical Engineering Research and Design, 87, 1276-1292 (2009). DOI: $10.1016 /$ j.cherd.2009.05.008

[5] Kubo S., Kadla J. F.: Poly(ethylene oxide)/organosolv lignin blends: Relationship between thermal properties, chemical structure, and blend behavior. Macromolecules, 37, 6904-6911 (2004). DOI: $10.1021 / \mathrm{ma} 0490552$

[6] Cateto C. A., Barreiro M. F., Rodrigues A. E., Belgacem M. N.: Kinetic study of the formation of ligninbased polyurethanes in bulk. Reactive and Functional Polymers, 71, 863-869 (2011). DOI: $10.1016 /$ j.reactfunctpolym.2011.05.007

[7] Gandini A.: Polymers from renewable resources: A challenge for the future of macromolecular materials. Macromolecules, 41, 9491-9504 (2008).

DOI: $10.1021 / \mathrm{ma} 801735 \mathrm{u}$

[8] Abad S., Santos V., Parajó J. C.: Multistage organosolv pulping: A method for obtaining pulps with low hemicellulose contents. Collection of Czechoslovak Chemical Communications, 68, 1163-1174 (2003). DOI: $10.1135 / \operatorname{cccc} 20031163$ 
[9] Vila C., Santos V., Parajó J. C.: Dissolving pulp from TCF bleached Acetosolv beech pulp. Journal of Chemical Technology and Biotechnology, 79, 1098-1104 (2004).

DOI: $10.1002 /$ jctb. 1090

[10] Ligero P., Villaverde J. J., de Vega A., Bao M.: Delignification of Eucalyptus globulus saplings in two organosolv systems (formic and acetic acid): Preliminary analysis of dissolved lignins. Industrial Crops and Products, 27, 110-117 (2008).

DOI: $10.1016 /$ j.indcrop.2007.08.008

[11] Jahan M. S., Chowdhury D. A. N., Islam M. K.: Atmospheric formic acid pulping and TCF bleaching of dhaincha (Sesbania aculeata), kash (Saccharum spontaneum) and banana stem (Musa Cavendish). Industrial Crops and Products, 26, 324-331 (2007). DOI: $10.1016 / \mathrm{j}$.indcrop.2007.03.012

[12] Lam H. Q., Le Bigot Y., Delmas M., Avignon G.: Formic acid pulping of rice straw. Industrial Crops and Products, 14, 65-71 (2001). DOI: $10.1016 / \mathrm{S} 0926-6690(00) 00089-3$

[13] Dapía S., Santos V., Parajó J. C.: Study of formic acid as an agent for biomass fractionation. Biomass and Bioenergy, 22, 213-221 (2002).

DOI: 10.1016/S0961-9534(01)00073-3

[14] Caridad R., Ligero P., Vega A., Bao M.: Formic acid delignification of Miscanthus sinensis. Cellulose Chemistry and Technology, 38, 235-244 (2004).

[15] Zhao X., Liu D.: Chemical and thermal characteristics of lignins isolated from Siam weed stem by acetic acid and formic acid delignification. Industrial crops and Products, 32, 284-291 (2010). DOI: $10.1016 /$ j.indcrop.2010.05.003

[16] Lachenal D., Mortha G., Sevillano R-M., Zaroubine M.: Isolation of residual lignin from softwood kraft pulp. Advantages of the acetic acid acidolysis method. Comptes Rendus Biologies, 327, 911-916 (2004).

DOI: $10.1016 /$ j.crvi.2004.09.002

[17] Cateto C. A., Barreiro M. F., Rodrigues A. E., Belgacem M. N.: Optimization study of lignin oxypropylation in view of the preparation of polyurethane rigid foams. Industrial and Engineering Chemistry Research, 48, 2583-2589 (2009).

DOI: $10.1021 / \mathrm{ie} 801251 \mathrm{r}$

[18] Peng Z., Chen F.: Synthesis and properties of ligninbased polyurethane hydrogels. International Journal of Polymeric Materials, 60, 674-683 (2011).

DOI: $10.1080 / 00914037.2010 .551353$

[19] Ni P., Thring R. W.: Synthesis of polyurethanes from solvolysis lignin using a polymerization catalyst: Mechanical and thermal properties. International Journal of Polymeric Materials, 52, 685-707 (2003). DOI: 10.1080/00914030304931

[20] Li Y., Ragauskas A. J.: Kraft lignin-based rigid polyurethane foam. Journal of Wood Chemistry and Technology, 32, 210-224 (2012).

DOI: $10.1080 / 02773813.2011 .652795$
[21] Ciobanu C., Ungureanu M., Ignat L., Ungureanu D., Popa V. I.: Properties of lignin-polyurethane films prepared by casting method. Industrial Crops and Products, 20, 231-241 (2004). DOI: $10.1016 /$ j.indcrop.2004.04.024

[22] Hatakeyama T., Izuta Y., Hirose S., Hatakeyama H.: Phase transitions of lignin-based polycaprolactones and their polyurethane derivatives. Polymer, 43, 1177-1182 (2002).

DOI: $10.1016 / \mathrm{S} 0032-3861(01) 00714-5$

[23] Zhang L., Huang J.: Effects of nitrolignin on mechanical properties of polyurethane-nitrolignin films. Journal of Applied Polymer Science, 80, 1213-1219 (2001). DOI: 10.1002/app.1206

[24] Zhou B. A., Sha Z., Li Y., Feng Y.: Modified polyurethane with acetic acid lignin and its property. China Pulp and Paper, 28, 22-25 (2009).

[25] Yang W.: Aorigele: Effect of annealing on properties of lignin-based polyurethane films. in ' $16^{\text {th }}$ International Symposium on Wood, Fiber and Pulping ChemistryProceedings, ISWFPC. Tianjin, China', 2, 1334-1337 (2011).

[26] Sarkar S., Adhikari B.: Synthesis and characterization of lignin-HTPB copolyurethane. European Polymer Journal, 37, 1391-1401 (2001).

DOI: $10.1016 / \mathrm{S} 0014-3057(00) 00264-0$

[27] Thring R. W., Ni P., Aharoni S. M.: Molecular weight effects of the soft segment on the ultimate properties of lignin-derived polyurethanes. International Journal of Polymeric Materials, 53, 507-524 (2004).

DOI: $10.1080 / 00914030490267627$

[28] Wang H., Ni Y., Jahan M. S., Liu Z., Schafer T.: Stability of cross-linked acetic acid lignin-containing polyurethane. Journal of Thermal Analysis and Calorimetry, 103, 293-302 (2011). DOI: $10.1007 / \mathrm{s} 10973-010-1052-\mathrm{x}$

[29] Flory P. J., Rehner J.: Statistical mechanics of crosslinked polymer networks II. Swelling. The Journal of Chemical Physics, 11, 521-526 (1943).

DOI: $10.1063 / 1.1723792$

[30] Huo S-P., Nie M-C., Kong Z-W., Wu G-M., Chen J.: Crosslinking kinetics of the formation of lignin-aminated polyol-based polyurethane foam. Journal of Applied Polymer Science, 125, 152-157 (2012). DOI: 10.1002/app.35401

[31] Cui G., Fan H., Xia W., Ai F., Huang J.: Simultaneous enhancement in strength and elongation of waterborne polyurethane and role of star-like network with lignin core. Journal of Applied Polymer Science, 109, 56-63 (2008). DOI: $10.1002 / a p p .28052$

[32] Luo N., Wang D-N., Ying S-K.: Hydrogen bonding between urethane and urea: Band assignment for the carbonyl region of FTi.r. spectrum. Polymer, 37, 30453047 (1996). DOI: 10.1016/0032-3861(96)89403-1 
[33] Srichatrapiumuk V. W., Cooper S. L.: Infrared thermal analysis of polyurethane block polymers. Journal of Macromolecular Science Part B: Physics, 15, 267-311 (1978). DOI: $10.1080 / 00222347808212599$

[34] Coleman M. M., Skrovanek D. J., Hu J., Painter P. C.: Hydrogen bonding in polymer blends. 1. FTIR studies of urethane-ether blends. Macromolecules, 21, 59-65 (1988).

DOI: $10.1021 / \mathrm{ma} 00179 \mathrm{a} 014$

[35] Jiang X., Li J., Ding M., Tan H., Ling Q., Zhong Y., Fu Q.: Synthesis and degradation of nontoxic biodegradable waterborne polyurethanes elastomer with poly $(\varepsilon-$ caprolactone) and poly(ethylene glycol) as soft segment. European Polymer Journal, 43, 1838-1846 (2007).

DOI: $10.1016 /$ j.eurpolymj.2007.02.029

[36] Yi H., Yan K-L.: Polyurethane modified with 3-aminopropyltriethoxysilane as wool antifelting agent. Journal of Applied Polymer Science, 109, 2169-2175 (2008). DOI: 10.1002/app.28012

[37] Desai S., Thakore I. M., Sarawade B. D., Devi S.: Structure-property relationship in polyurethane elastomers containing starch as a crosslinker. Polymer Engineering and Science, 40, 1200-1210 (2000). DOI: $10.1002 /$ pen.11247

[38] Bonini C., D’Auria M., Emanuele L., Ferri R., Pucciariello R., Sabia A. R.: Polyurethanes and polyesters from lignin. Journal of Applied Polymer Science, 98, 1451-1456 (2005). DOI: $10.1002 / a p p .22277$

[39] Xia Y., Larock R. C.: Preparation and properties of aqueous castor oil-based polyurethane-silica nanocomposite dispersions through a sol-gel process. Macromolecular Rapid Communication, 32, 1331-1337 (2011).

DOI: $10.1002 /$ marc.201100203
[40] Sormana J-L., Meredith J. C.: High-throughput discovery of structure-mechanical property relationships for segmented poly(urethane-urea)s. Macromolecules, 37, 2186-2195 (2004).

DOI: $10.1021 / \mathrm{ma} 035385 \mathrm{v}$

[41] Noh S. H., Choi H. S., Noh S. T.: Synthesis and application of water-based urethane acrylate crosslinking agent containing unsaturated group. Journal of Applied Polymer Science, 78, 1216-1223 (2000).

DOI: 10.1002/1097-4628(20001107)78:6<1216::AIDAPP60>3.0.CO;2-8

[42] Cui G., Xia W., Chen G., Wei M., Huang J.: Enhanced mechanical performances of waterborne polyurethane loaded with lignosulfonate and its supramolecular complexes. Journal of Applied Polymer Science, 106, 4257-4263 (2007).

DOI: $10.1002 / a p p .27077$

[43] Sanchis M. R., Calvo O., Fenollar O., Garcia D., Balart R.: Characterization of the surface changes and the aging effects of low-pressure nitrogen plasma treatment in a polyurethane film. Polymer Testing, 27, 7583 (2008).

DOI: $10.1016 /$ j.polymertesting.2007.09.002

[44] Chattopadhyay D. K., Sreedhar B., Raju K. V. S. N.: Effect of chain extender on phase mixing and coating properties of polyurethane ureas. Industrial and Engineering Chemistry Research, 44, 1772-1779 (2005). DOI: $10.1021 / \mathrm{ie} 0492348$

[45] Sreedhar B., Chattopadhyay D. K., Swapna V.: Thermal and surface characterization of polyurethane-urea clay nanocomposite coatings. Journal of Applied Polymer Science, 100, 2393-2401 (2006).

DOI: $10.1002 /$ app. 23140 